\title{
Performance of Suffolk and Texel sheep grazing pastures that presented contrasting levels of parasite challenge
}

J P Hanrahan, B Good

Teagasc, Co. Galway, Ireland

Email: seamus.hanrahan@teagasc.ie

Introduction Suffolk sheep have substantially lower faecal egg counts for gastrointestinal nematode parasites than cograzed Texel sheep and these breeds also have different nematode burdens in the abomasum and small intestine (Hanrahan and Crowley, 1999; Good et al., 2006). The impact of these differences in resistance to parasite infection on animal performance needs to be established in order to determine whether there are breed differences in resilience to gastrointestinal parasite infection. The objective of this study was to evaluate differences in breed performance when grazed under contrasting level of parasite challenge. The null hypothesis was that breed differences in lamb growth rate are independent of level of parasite challenge.

Materials and methods The study was repeated over two grazing seasons and the animals involved (143 Suffolk and 151 Texel lambs) were from the purebred flocks of Suffolk and Texel sheep maintained at this research centre. The ewes in these flocks are housed between December and lambing (early to mid March) and are turned out, with their lambs, to pasture within 2 to 3 days after parturition. Routine animal performance records include ewe weight and condition score post mating, 5 weeks post lambing and at weaning and ewe condition score immediately post lambing; lambs were weighed at birth and at 5, 10 and 14 weeks (weaning) of age. In present study all lambs were also weighed at 18 weeks of age. Level of nematode infection was monitored by faecal egg counts at regular intervals up to 18 weeks of age and the number of infective larvae on pastures was evaluated weekly in year 1. Two pastures with different grazing histories were used: 'Clean' = sward established in the autumn prior to year 1 of this study and not grazed by sheep prior to turnout in spring of year 1, 'Dirty' = permanent old pasture that had been grazed by sheep only for at least 10 years prior to year 1 . The management of the 'Clean' sward during the late summer and autumn of year 1 was designed to minimise any accumulation of infective larvae so that herbage larval challenge in year 2 was maintained at a low level. . Ewes were assigned at random, within breed and lambing date, to treatment and were managed as a single group within treatment. Anthelmintic treatment of lambs during the period to 18 weeks of age was as follows: all lambs were dosed at 5 weeks of age and no further anthelmintic was administered until after 18 weeks of age. All ewes were dosed post lambing, prior to turnout, to minimise larval output onto the 'Clean' pasture. Data were analysed using mixed model procedures.

Results The objective of providing contrasting levels of parasite challenge between the 'Clean' and 'Dirty' pastures was achieved as shown by contrasting faecal egg counts (40/g for Clean $v 400 / \mathrm{g}$ for Dirty at 18 weeks; the 'clean' group had essentially zero counts at 14 weeks whereas the dirty group averaged 300 eggs/g) and the number of infective larvae per 1 $\mathrm{kg}$ herbage dry matter (near zero for 'Clean'; over 500 for 'Dirty' between mid June and mid August). Data on lamb growth are summarised in Table 1. There was a highly significant breed x pasture type interaction for weights at 14 and 18 weeks of age and growth rate from 5 weeks to weaning. These interactions reflected the much greater impact of "Dirty" grazing on Suffolk lambs. At 18 weeks of age Suffolk lambs on 'Dirty' pasture were $4.6 \mathrm{~kg}$ lighter than Suffolk lambs on "Clean" pasture whereas the corresponding difference for Texel lambs was only $1 \mathrm{~kg}$. There was no evidence for an effect of grazing treatment on lamb growth rate between birth and 5 weeks and it is evident that the negative impact of dirty grazing on Suffolk lambs increased as the season progressed (Table 1). There was also evidence for a breed $\mathrm{x}$ grazing treatment interaction for some aspects of ewe performance. Thus, live weight of Texel ewes at weaning was unaffected by grazing system whereas Suffolk ewes on the "Dirty" pasture were $4.7 \mathrm{~kg}$ lighter than those on 'Clean' pasture $(\mathrm{P}<0.05)$.

Table 1 Lamb growth as a function of breed and level of parasite challenge

\begin{tabular}{|c|c|c|c|c|c|c|}
\hline \multirow[t]{2}{*}{ Breed } & \multirow[t]{2}{*}{ Pasture type } & \multicolumn{2}{|c|}{ Live weight $(\mathrm{kg})$ at } & \multicolumn{3}{|c|}{ Growth rate g/day } \\
\hline & & 14 weeks & 18 weeks & 0 to 5 weeks & 5 to 14 weeks & 14 to 18 weeks \\
\hline \multirow[t]{2}{*}{ Texel } & Clean & 34.6 & 39.6 & 322 & 302 & 149 \\
\hline & Dirty & 34.3 & 38.6 & 334 & 271 & 129 \\
\hline \multirow[t]{2}{*}{ Suffolk } & Clean & 36.7 & 41.7 & 318 & 332 & 140 \\
\hline & Dirty & 34.5 & 37.1 & 330 & 268 & 91 \\
\hline \multicolumn{2}{|l|}{ s.e. } & 0.49 & 0.51 & 5.1 & 7.3 & 10.1 \\
\hline \multicolumn{2}{|c|}{ Breed $\mathrm{x}$ Pasture type interaction } & $\mathrm{P}<0.02$ & $\mathrm{P}<0.001$ & $\mathrm{P}=0.9$ & $\mathrm{P}<0.02$ & $P=0.4$ \\
\hline
\end{tabular}

Conclusions Suffolk lambs grow faster than Texel lambs when parasite infection is minimised. The interaction between breed and level of parasite challenge shows that the breed differences in lamb growth depend on level of parasite challenge. The impact of parasite infection on Suffolk lambs increases as the grazing season progresses.

\section{References}

Good, B., Hanrahan, J.P., Crowley, B.A. and Mulcahy, G. 2006 Veterinary Parasitology 136, 317-327.

Hanrahan, J.P. and Crowley, B.A. 1999 Proceedings of $50^{\text {th }}$ European Association for Animal Production (Zurich), 4 pages. 